\title{
Acaricide-impaired functional predation response of the phytoseiid mite Neoseiulus baraki to the coconut mite Aceria guerreronis
}

\author{
D. B. Lima ${ }^{1,5}$ - J. W. S. Melo ${ }^{2}$ M. G. C. Gondim Jr. ${ }^{1}$ R. N. C. Guedes ${ }^{3}$. \\ J. E. M. Oliveira ${ }^{4} \cdot$ A. Pallini $^{3}$
}

Accepted: 31 March 2015/Published online: 7 April 2015

(C) Springer Science+Business Media New York 2015

\begin{abstract}
Acaricides may interfere with a myriad of interactions among arthropods, particularly predator-prey interactions. The coconut mite, Aceria guerreronis Keifer (Acari: Eriophyidae), and its phytoseiid predator, Neoseiulus baraki (Athias-Henriot) (Acari: Phytoseiidae), provide an opportunity to explore such interference because the former is a key coconut pest species that requires both predation and acaricide application for its management. The objective of the present study was to assess the effect of the acaricides abamectin, azadirachtin and fenpyroximate on the functional response of $N$. baraki to A. guerreronis densities. The following prey densities were tested: 5, 10, 20, 40 and 80 preys. The type of functional response and prey handling time $(T h)$ were not altered by the acaricides. However, the attack rate $\left(a^{\prime}\right)$ was modified by abamectin and fenpyroximate, and the consumption peak was reduced by abamectin. All of the acaricides allowed for the maintenance of the predator in the field, but
\end{abstract}

D. B. Lima

deboralima_85@yahoo.com.br

1 Departamento de Agronomia - Entomologia, Universidade Federal Rural de Pernambuco, Av. Dom Manoel de Medeiros s/n, Dois Irmãos, Recife, PE 52171-900, Brazil

2 Departamento de Fitotecnia, Universidade Federal do Ceará, Fortaleza, CE, Brazil

3 Departamento de Entomologia, Universidade Federal de Viçosa, Av. Peter Henry Rolfs, s/n, Campus Universitário, Viçosa, MG 36570-000, Brazil

4 Departamento de Entomologia, Embrapa Semiárido, Petrolina, PE 56302-970, Brazil

5 Departamento de Agronomia (Fitossanidade), Universidade Federal Rural de Pernambuco, Av. Dom Manoel de Medeiros s/n, Bairro Dois Irmãos, Recife, PE 52171-900, Brazil exposure to abamectin and fenpyroximate compromised prey consumption.

Keywords Acaricides · Prey consumption · Predatorprey interaction - Attack rate

\section{Introduction}

Pesticides may interfere with a myriad of arthropod interactions, but the focus on mortality in the assessment of pesticide impacts on biological systems may preclude the recognition of important sublethal effects of these compounds. This trend is shifting, but broader assessments have remained limited to relatively few species and realistic scenarios (Desneux et al. 2007; Cutler 2013; Guedes and Cutler 2014). The coconut production system provides an interesting model for studying acaricide-mediated predator-prey interactions and their potential consequences for integrated pest management.

Aceria guerreronis Keifer (Acari: Eriophyidae) is one of the main pests of coconut palm, Cocos nucifera L., worldwide (Moore and Howard 1996; Haq et al. 2002; Negloh et al. 2011). This mite inhabits the perianth of the coconut and feeds on the meristematic tissue, causing necrosis of the epidermis and the coconuts to fall. Biological control of $A$. guerreronis by predators has been extensively studied (Aratchige et al. 2007; Lawson-Balagbo et al. 2008; Negloh et al. 2011; Lima et al. 2012), and Neoseiulus baraki (Athias-Henriot) is one of the most common predators associated with A. guerreronis within the perianth (Aratchige et al. 2007; Negloh et al. 2011; Lima et al. 2012).

Neoseiulus baraki can complete its development with $A$. guerreronis as its sole food source (Lawson-Balagbo et al. 
2008; Domingos et al. 2010); the mite is its preferred prey, and it is able to detect cues from this pest (Melo et al. 2011). Neoseiulus baraki has high predatory capacity and morphological traits that facilitate its entry into the perianth region, which optimises its foraging and predation of the coconut mite (Lima et al. 2012). However, although the use of predators as biological control agents represents a promising alternative to pesticides, acaricide spraying remains the control method most used against $A$. guerreronis (Monteiro et al. 2012; Lima et al. 2015).

Acaricides are only effective if applied frequently, beginning when the coconuts are still developing (Moore and Howard 1996; Ramaraju et al. 2002). However, frequent use of acaricides can lead to selection for insecticide-resistant populations, pest resurgence, secondary pest outbreaks, or even compromised performance of natural enemies (Cranham and Helle 1985; Omoto et al. 2000; van Leeuwen et al. 2010; Cordeiro et al. 2013). Recent studies have suggested the possible compatibility of natural enemies and acaricides in controlling A. guerreronis, which could lead to higher mortality rates of this pest (Lima et al. 2013a, b).

Integrated pest management aims to reduce pest populations to levels that do not cause economic losses through a combination of control methods, especially biological control and chemical control (Croft 1990), so knowledge of the effects of pesticides on biological control agents is important (Desneux et al. 2007). Predators can be exposed to pesticides through direct spraying, contact with contaminated surfaces during foraging, or feeding on contaminated prey (Jepson 1989; Ahmad et al. 2003; Hua et al. 2004; Torres and Ruberson 2004).

The toxicity, selectivity, and sublethal effects of pesticides have been studied in diverse mite pest and predator systems (Poletti et al. 2007; Teodoro et al. 2009; Hamedi et al. 2011; Lima et al. 2013a, b). Pesticides may have lethal or sublethal effects on predators, the latter of which has been receiving increasing attention (e.g., Desneux et al. 2007; Guedes and Cutler, 2014). Sublethal effects allow individuals to survive exposure to pesticides (Desneux et al. 2007), but these effects can lead to physiological and/ or behavioural processes that may compromise the efficiency of a natural enemy by, for example, altering functional response, life table parameters, and foraging (Wang and Shen 2002; Poletti et al. 2007; Nadimi et al. 2009; Teodoro et al. 2009; Rezác et al. 2010; Hamedi et al. 2011). Previous studies have been conducted with $N$. baraki exposed to acaricides used for controlling A. guerreronis and have revealed altered instantaneous rate of increase, walking patterns, and survival in the predator (Lima et al. 2013a, b). Additionally, some acaricides have been shown to repel and/or irritate the predator (Lima et al. 2013a). Thus, this study aimed to evaluate the compatibility of the acaricides abamectin, fenpyroximate, and azadirachtin with the use of $N$. baraki by observing the action of these products on the predator's functional response.

\section{Materials and Methods}

\section{Rearing N. baraki}

Cocos nucifera coconuts were collected from Itamaracá Island, the state of Pernambuco, Brazil $\left(07^{\circ} 46^{\prime} \mathrm{S}, 34^{\circ} 52^{\prime} \mathrm{W}\right)$ and transported to the Laboratory of Acarology of the Federal Rural University of Pernambuco (Universidade Federal Rural de Pernambuco-UFRPE). The plants from which the coconuts were taken have not been sprayed with pesticides for more than 10 years. The coconuts were kept in the laboratory $\left(27 \pm 1.0^{\circ} \mathrm{C}, 75 \pm 10 \% \mathrm{RH}\right.$, and a 12 -h photoperiod) until used. Approximately 100 N. baraki females were collected from the perianth of the coconuts and transferred to $16 \mathrm{~cm}$ diameter rearing units consisted of plastic trays containing $1 \mathrm{~cm}$ thick polyethylene foam, on to which was placed a filter paper and $1 \mathrm{~mm}$ thick black PVC. In each unit, the PVC disk was surrounded by hydrophilic cotton moistened with distilled water to prevent mites from escaping. Aceria guerreronis was provided as food on perianth fragments $\left(\sim 0.5 \mathrm{~cm}^{3}\right)$ containing approximately 300 individuals in different stages of development. The food was replenished every 2 days as 5 perianth fragments per rearing unit. The A. guerreronis were removed from coconuts and stored up to 7 days. The rearing units were kept in an incubator at $27 \pm 1.0{ }^{\circ} \mathrm{C}$, $75 \pm 10 \% \mathrm{RH}$, and a 12-h photoperiod.

\section{Acaricides}

The following acaricides were administered in their respective registered concentrations to control A. guerreronis in coconut palms (Agrofit 2014): abamectin (Vertimec 18 $\mathrm{CE}, 18 \mathrm{~g}$ a.i. (active ingredient) $1^{-1}$, emulsifiable concentrate, Syngenta, São Paulo, São Paulo, Brazil) at $13.5 \mathrm{mg}$ a.i. $\mathrm{l}^{-1}$, azadirachtin (AzaMax, $12 \mathrm{~g}$ a.i. $\mathrm{l}^{-1}$, emulsifiable concentrate, DVA Brazil, Campinas, São Paulo, Brazil) at $30 \mathrm{mg}$ a.i. $1^{-1}$, and fenpyroximate (Ortus $50 \mathrm{SC}$, $50 \mathrm{~g}$ a.i. $1^{-1}$, suspension concentrate, Arysta LifeScience, Salto de Pirapora, São Paulo, Brazil) at $100 \mathrm{mg}$ a.i. $^{-1}$.

\section{Testing the consumption of dead prey}

Before performing the functional response experiment, dead prey without acaricide residue were offered to $N$. baraki to assess whether they would be consumed because some acaricides can kill A. guerreronis before they are 
predated. The method was adapted from the one used by Lima et al. (2012), and the experimental unit was similar to the rearing unit previously described, except for the black PVC which was replaced by fragments of Canavalia ensiformis $\mathrm{L}$. leaves $(4 \times 4 \mathrm{~cm})$. The preys were killed by touching them with a single-bristle brush and considered dead when no movement was observed in the legs. Ten dead prey individuals were offered on perianth fragments of $1 \mathrm{~cm}^{3}$, and one visually healthy, fertilised $N$. baraki female was transferred from the rearing unit to each experimental unit. Each experimental unit comprised one replicate, and a total of ten replicates were performed. After $24 \mathrm{~h}$, the number of dead prey consumed was calculated, and it was observed that $N$. baraki consumes dead prey. Thus, the A. guerreronis individuals found during the evaluation of the functional response were not consumed due to the effect of the acaricides. The entire experiment was conducted under the same conditions of temperature, humidity, and photoperiod used for rearing.

\section{Effect of acaricides on the functional response}

The method used to evaluate the effect of insecticides on the functional response was the same as used in the dead prey consumption test. However, the fragments of $C$. ensiformis leaves and perianth fragments were dipped (for $5 \mathrm{~s}$ ) into distilled water or solutions containing the recommended concentrations of the acaricides for controlling A. guerreronis. After immersion, the leaf and perianth fragments were left to dry for $30 \mathrm{~min}$. Next, A. guerreronis were transferred to perianth fragments at densities of 5, 10, 20, 40, and 80 individuals per fragment. Each experimental unit that contained one fertilised predator female comprised one replicate, and there were a total of 20 replicates for each density. After $24 \mathrm{~h}$, the number of prey (alive or dead) present in the arena was calculated, and the number of prey consumed was obtained by subtraction.

The evaluation method described above can lead to an overestimation of prey consumption because acaricides can repel and/or irritate the prey, causing them to try to escape the experimental arena. To correct for the overestimated prey consumption, a blank test was performed for each density of each treatment, following the same method described above, but without introducing the predator. Thus, the percentage of prey lost during the experimental period was quantified as a possible correction of the predator's consumption, which was only used when the total percentage of mites lost was higher than $10 \%$. This correction was only performed for the density of 80 prey individuals/ arena treated with azadirachtin, for which Abbot's (1925) formula was used.

\section{Data analyses}

For each treatment (control and each acaricide), logistic regression curves were fitted between the proportion of prey consumed and the density of prey, following the protocol by Juliano (1993) (Proc CATMOD; SAS Institute 2002), to determine the significance of the regression coefficients and the sign of the linear coefficient, which determined the type of functional response. Holling $(1959,1961)$ characterised 3 functional responses: Type I-a linear increase in the number of prey ingested by the predator up to a maximum as prey density increases; Type II-the number of prey attacked by the predator quickly increases because of high prey availability followed by a gradual decrease until stabilisation (plateau); Type III-the response is sigmoid and approaches a higher asymptote. Using a modified version of the same protocol, the estimated proportion of dead prey was obtained (modification: Proc PRINT instead of Proc PLOT), and the proportion of prey consumed was plotted as a function of prey density using SigmaPlot ${ }^{\circledR}$ (Systat Software, San Jose, CA). The attack rate $\left(a^{\prime}\right)$ and handling time $(T h)$ parameters were calculated with nonlinear least squares regression (Proc NLIN of the SAS software, SAS Institute 2002) using the "full model" of the protocol by Juliano (1993) for a Type II functional response. The $a^{\prime}$ and $T h$ values were compared among the treatments using $95 \%$ confidence intervals.

Logistic regression curves were fitted for each treatment (control and each acaricide) between the number of consumed prey and prey density using PROC REG in SAS software (SAS Institute 2002). After fitting the linear model $(P<0.05)$, the slopes of the regressions were compared using PROC MIXED in SAS software (SAS Institute 2002).

Peak consumption was calculated for each treatment based on the reciprocal of $T h\left(\frac{1}{T h}\right)$ and compared based on the confidence interval. The mean variation in prey consumption for each predator at each density $(\Delta N a)$ was calculated following the equation of Poletti et al. (2007): $\Delta N a=\frac{\left(N a_{N \max }-N a_{\text {min }}\right)}{\left(N_{\max }-N_{\min }\right)}$ where $N a_{N \min }$ and $N a_{N \max }$ are the minimum and maximum number of prey consumed by the predator, respectively, and Nmin and Nmax correspond to the minimum and maximum densities. The consumption variation data were analysed using ANOVA, and the means were compared using Tukey's HSD test $(P=0.05)$ in SAS (SAS Institute 2002). The mean variation in consumption was plotted as a function of handling time; variations closest to the control indicated little or no effect on prey consumption by $N$. baraki. 


\section{Results}

Regardless of acaricide exposure, the model of the variation in the number of prey killed by predators remained unaltered, and prey consumption stabilised at higher densities (Fig. 1a). This model corresponded to a Type II functional response (Table 1; Fig. 1a). Prey handling time by $N$. baraki (Th) remained unaltered when the predator was exposed to acaricides and ranged from 0.26 and $0.58 \mathrm{~h}$. However, the acaricides fenpyroximate and abamectin altered the $N$. baraki attack rate $\left(a^{\prime}\right)$, which was lower than that observed in the control treatment (Table 2).

Differences in the slopes of the regressions between prey consumption and the tested densities were observed among the treatments $(-21.37 \geq \mathrm{t} \leq 7.61 ; P \leq 0.01)$. A higher slope was observed for azadirachtin followed by the control, fenpyroximate, and abamectin (Fig. 1b).

Significant differences at the $5 \%$ level occurred in peak consumption when the $95 \%$ confidence intervals of the estimates did not overlap [control: 3.57 (3.35-3.68);
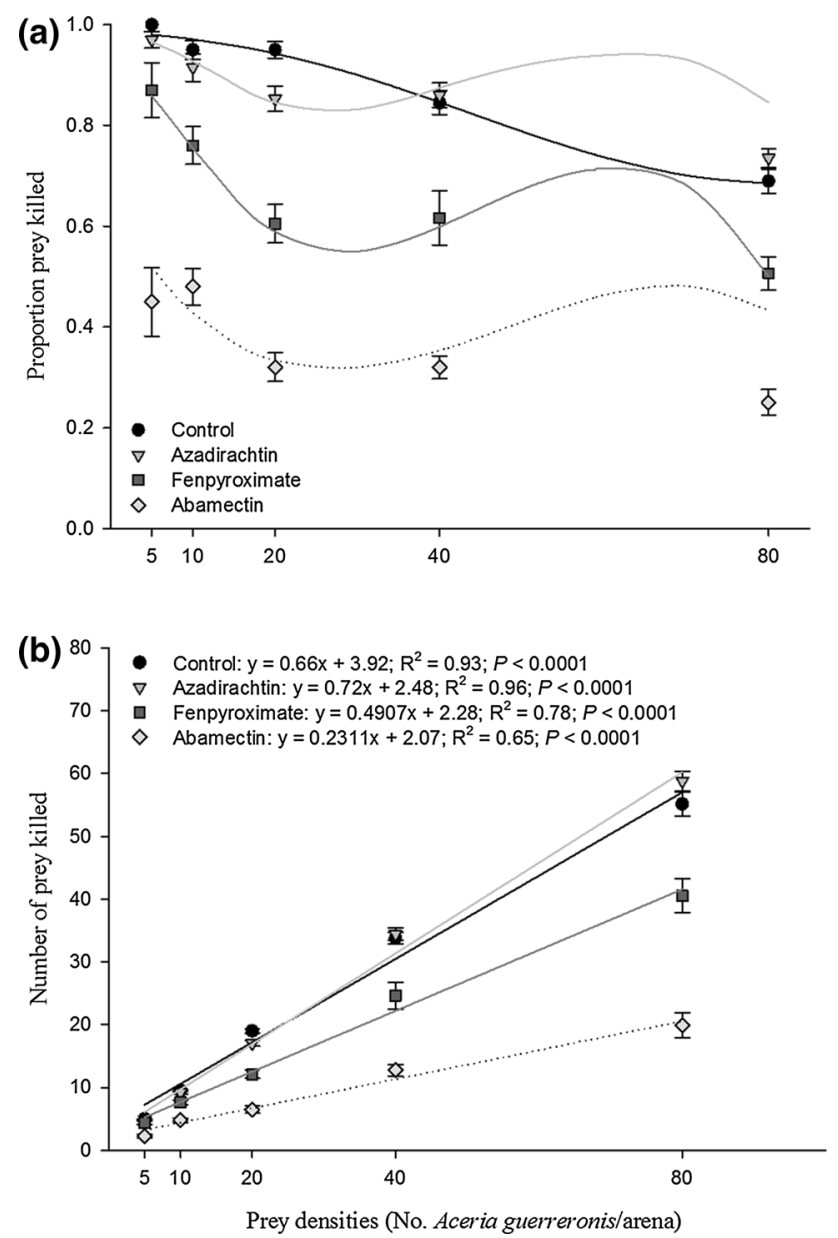

Fig. 1 Regression of proportion (mean $\pm \mathrm{SE}$ ) (a) and number (mean $\pm \mathrm{SE}$ ) (b) of Aceria guerreronis killed per Neoseiulus baraki azadirachtin: $3.23 \quad$ (3.16-3.26); fenpyroximate: 3.85 (3.19-4.16) and abamectin: $1.72(1.45-1.86)]$. The peak consumption of prey estimated for the predator in the control treatment was $3.57 \mathrm{prey} / \mathrm{h}$ which decreased by $52 \%$ when the predator was exposed to abamectin, distinct from the other acaricides. The peak consumption values were similar to the control when the predator was exposed to fenpyroximate and azadirachtin.

There was a difference in the mean variations in prey consumption by $N$. baraki $\left(\mathrm{DF}=3 ; \quad \mathrm{F}_{3,73}=59.24\right.$; $P<0.0001$ ). A higher degree of variation was observed in the control and azadirachtin treatments, and there was no difference between the treatments. This indicates little or no effect of azadirachtin on $N$. baraki predatory activity. Fenpyroximate and abamectin caused variations in prey consumption lower than the control, which indicates impairment of predatory activity by these acaricides. The acaricide abamectin exhibited the lowest variation in prey consumption (Fig. 2).

\section{Discussion}

Functional response describes changes in a predator's feeding rate as a function of food density (Holling 1959). In this study, the acaricides azadirachtin, fenpyroximate, and abamectin did not alter the functional response type of N. baraki. However, fenpyroximate and abamectin compromised $N$. baraki predatory activity by altering the attack rate and consequently reducing the mean consumption of A. guerreronis by $N$. baraki.

Attack rate determines the capture ability of a predator within a certain area (Holling 1959), and this parameter was lower when $N$. baraki was exposed to fenpyroximate and abamectin, indicating that exposure to such products decreases the predator's potential for capturing prey. This decrease may be due to irritation and/or altered locomotion parameters. According to Lima et al. (2013a), fenpyroximate irritates $N$. baraki, causing a behavioural change that leads the predator to avoid the pesticide after contact with its residue (Cordeiro et al. 2010; Lima et al. 2013a). Thus, contact with fenpyroximate residue may have prevented encounters with A. guerreronis and, consequently, reduced prey consumption. Abamectin does not appear to cause irritability, but this product may compromise behavioural parameters in $N$. Baraki, especially walking speed (Lima et al. 2013a). Due to the possible changes in these parameters, the search for prey by $N$. baraki was hindered.

Handling time did not significantly increase following the exposure of $N$. baraki to acaricides. Although statistically similar, the handling time by $N$. baraki when exposed to abamectin was 2.7 times higher than that observed in the 
Table 1 Holling disc equation and type of functional response of Neoseiulus baraki eating Aceria guerreronis in each treatment

\begin{tabular}{|c|c|c|c|c|c|c|c|c|c|}
\hline \multirow[t]{2}{*}{ Treatments } & \multirow[t]{2}{*}{ Holling disc equation } & \multirow[t]{2}{*}{$\chi^{2}$} & \multirow[t]{2}{*}{$\mathrm{DF}$} & \multirow[t]{2}{*}{$P$} & \multicolumn{4}{|c|}{ Coefficient of logistic regression } & \multirow{2}{*}{$\begin{array}{l}\text { Type } \\
\text { FR }^{\mathrm{e}}\end{array}$} \\
\hline & & & & & $\mathrm{I}^{\mathrm{a}}(P)$ & $\mathrm{L}^{\mathrm{b}}(P)$ & $\mathrm{Q}^{\mathrm{c}}(P)$ & $\mathrm{C}^{\mathrm{d}}(P)$ & \\
\hline Control & $\mathrm{y}=\frac{\left(0.0005 \mathrm{x}^{2}\right)-(0.09 \mathrm{x})+4.32}{1+\left[\left(0.0005 \mathrm{x}^{2}\right)-(0.09 \mathrm{X})+4.32\right]}$ & 219.59 & 97 & $<.0001$ & $\begin{array}{l}4.32 \\
(<.0001)\end{array}$ & $\begin{array}{l}-0.09 \\
(<.0001)\end{array}$ & $\begin{array}{l}0.0005 \\
(0.0007)\end{array}$ & - & II \\
\hline Azadirachtin & $\mathrm{y}=\frac{\left.-\left(0.00005 \mathrm{x}^{3}\right)+\left(0.0067 \mathrm{x}^{2}\right)-(0.25 * \mathrm{x})+4.42\right]}{1-\left[\left(0.00005 \mathrm{X}^{3}\right)+\left(0.0067 \mathrm{X}^{2}\right)-(0.25 * \mathrm{X})+4.42\right]}$ & 194.12 & 96 & $<.0001$ & $\begin{array}{l}4.42 \\
(<.0001)\end{array}$ & $\begin{aligned} &-0.25 \\
&(0.0003)\end{aligned}$ & $\begin{array}{l}0.0067 \\
(0.0003)\end{array}$ & $\begin{array}{r}-0.00005 \\
(0.0002)\end{array}$ & II \\
\hline Fenpyroximate & $y=\frac{-\left(0.00004 x^{3}\right)+\left(0.0054 x^{2}\right)-(0.21 x)+2.78}{1-\left[\left(0.00004 X^{3}\right)+\left(0.0054 X^{2}\right)-(0.21 X)+2.78\right]}$ & 458.89 & 96 & $<.0001$ & $\begin{array}{l}2.79 \\
(<.0001)\end{array}$ & $\begin{array}{l}-0.21 \\
(<.0001)\end{array}$ & $\begin{array}{l}0.0054 \\
(<.0001)\end{array}$ & $\begin{array}{r}-0.00004 \\
(<.0001)\end{array}$ & II \\
\hline Abamectin & $y=\frac{-\left(0.00002 x^{3}\right)+\left(0.0029 x^{2}\right)-(0.11 x)+0.56}{1-\left[\left(0.00002 x^{3}\right)+\left(0.0029 X^{2}\right)-(0.11 X)+0.56\right]}$ & 260.79 & 96 & $<.0001$ & $\begin{array}{l}0.56 \\
(0.0649)\end{array}$ & $\begin{array}{l}-0.11 \\
(0.0017)\end{array}$ & $\begin{array}{l}0.0029 \\
(0.0065)\end{array}$ & $\begin{array}{r}-0.00002 \\
(0.0085)\end{array}$ & II \\
\hline
\end{tabular}

\footnotetext{
${ }^{\mathrm{a}}$ Intercept

${ }^{\mathrm{b}}$ Linear

${ }^{\mathrm{c}}$ Quadratic

d Cubic

e Type of functional response
}

Table 2 Parameters $( \pm \mathrm{SE})$ of functional responses of Neoseiulus baraki fed with Aceria guerreronis and respective confidence intervals in each treatment

\begin{tabular}{lll}
\hline Treatment & $a^{\prime} \pm$ SE $(95 \%$ CI $)$ & Th \pm SE $(95 \%$ CI $)$ \\
\hline Control & $0.13 \pm 0.02(0.09-0.17)$ & $0.28 \pm 0.03(0.22-0.33)$ \\
Azadirachtin & $0.13 \pm 0.02(0.10-0.17)$ & $0.31 \pm 0.02(0.27-0.36)$ \\
Fenpyroximate & $0.05 \pm 0.01(0.03-0.07)^{\mathrm{a}}$ & $0.26 \pm 0.07(0.12-0.40)$ \\
Abamectin & $0.02 \pm 0.01(0.01-0.03)^{\mathrm{a}}$ & $0.58 \pm 0.15(0.29-0.87)$
\end{tabular}

Attack rate coefficient $a^{\prime}$ (in units of the proportion of prey captured by predator per unit of searching time) and handling time $T h$ (in units of the proportion of $24 \mathrm{~h}$ exposure period)

${ }^{a}$ Significantly different from control at $5 \%$ level when $95 \%$ confidence intervals of estimates did not overlap

absence of acaricide. This may explain the $52 \%$ decrease in the $N$. baraki consumption peak. Handling time includes the time needed by the predator to identify, capture, attack, and consume prey (Holling 1959). Therefore, high Th values suggest that the predator spends more time with a particular prey item and thus takes longer to go in search of another. This can be observed through the variation in prey consumption where the abamectin treatment, which results in the highest handling time, exhibited lower variation in the number of prey consumed. Altered $T h$ values in mites and insects have been observed after exposure to neurotoxic pesticides (Wang and Shen 2002; Poletti et al. 2007; Rezác et al. 2010).

Fenpyroximate and abamectin decreased A. guerreronis consumption by $N$. baraki and also exhibited lower mean variations in consumption. This decrease was expected as these acaricides can alter the behavioural parameters of this predator (Lima et al. 2013a). Additionally, both of these acaricides altered the $N$. baraki attack rate. Among all of

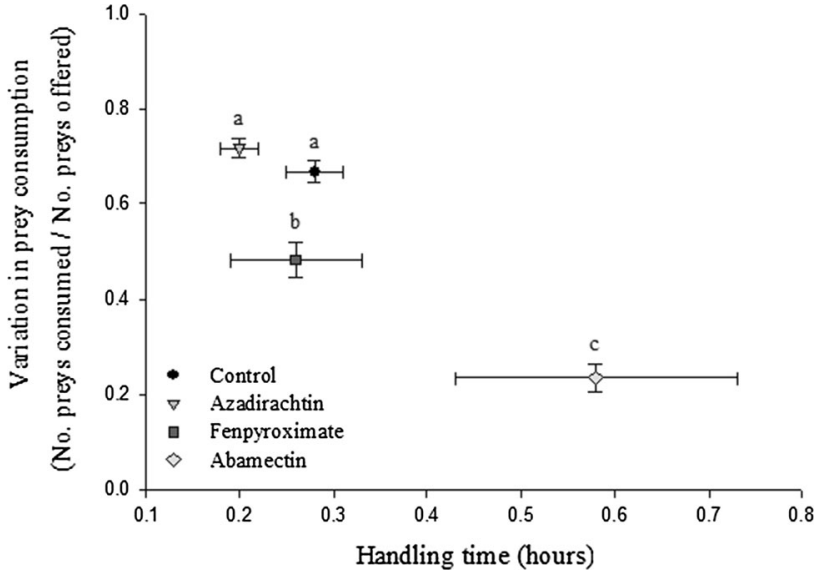

Fig. 2 Mean variation in consumption of Aceria guerreronis (mean $\pm \mathrm{SE}$ ) as a function of variation in handling time (mean $\pm \mathrm{SE}$ ) by Neoseiulus baraki. Different letters indicate significant differences between treatments by the Tukey's HSD test $(P<0.05)$

the acaricides, azadirachtin was the only one that did not decrease consumption, so it is possible that azadirachtin does not have a significant effect on $N$. baraki predation.

Contact of $N$. baraki with acaricide may take place since the onset of colonization (when the plants are approximately 2 months old), while walking on the coconut surface and penetrating it via the bract. This contact exposure likely lasts until mites disperse away from coconuts frequently treated with acaricides [about 15 days apart, but longer intervals have been suggested (Melo et al. 2012)]. According to Lima et al. (2013b), the acaricides studied here lead to low (acute) toxicity to N. baraki, but fenpyroximate and abamectin are lethal to A. guerreronis at levels lower than those used in this study (Monteiro et al. 
2012; Lima et al. 2013b). Thus, $N$. baraki may reduce the population of A. guerreronis under field conditions (i.e., under acaricide use).

All of the acaricides from our study allowed for the maintenance of the predator in the field, but exposure to abamectin and fenpyroximate compromised prey consumption. This means that combining these acaricides with biological control is possible for A. guerreronis management, but predator efficiency is reduced with exposure to abamectin and fenpyroximate. However, evaluating the effects of acaricides on predator foraging and biology through further experiments is necessary to evaluate the risks from these compounds to $N$. baraki and the effectiveness of $N$. baraki as a biological control agent with the simultaneous use of these acaricides. In addition, the compatibility of the acaricides with the use of $N$. baraki should be further investigated under field conditions.

Acknowledgments We thank the following Brazilian agencies for their financial support: Pernambuco State Foundation for Research Aid (FACEPE), CAPES Foundation (Brazilian Ministry of Education), and the National Council of Scientific and Technological Development (CNPq).

Conflict of interest The authors declare that they have no conflict of interest.

Ethical standards This study did not involve any endangered or protected species. The specie studied is a species of predatory mite from a colony maintained in laboratory, where the experiments were performed and no specific permission was required.

\section{References}

Abbott WS (1925) A method of computing the effectiveness of an insecticide. J Econ Entomol 18:265-267

Agrofit (2014) Sistema de agrotóxicos Fitossanitários do Ministério da Agricultura, Pecuária e Abastecimento, http://extranet.agri cultura.gov.br/agrofit_cons/principal_agrofit_cons

Ahmad M, Ossiewatsch HR, Basedow T (2003) Effects of neem treated aphids as food/hosts on their predators and parasitoids. J Appl Entomol 127:458-464

Aratchige NS, Sabelis MW, Lesna I (2007) Plant structural changes due to herbivory: do changes in Aceria-infested coconut fruits allow predatory mites to move under the perianth? Exp Appl Acarol 43:97-107

Cordeiro EMG, Corrêa AS, Venzon M, Guedes RNC (2010) Insecticide survival and behavioral avoidance in the lacewings Chrysoperla externa and Ceraeochrysa cubana. Chemosphere 81:1352-1357

Cordeiro EMG, De Moura ILT, Fadini MAM, Guedes RNC (2013) Beyond selectivity: are behavioral avoidance and hormesis likely causes of pyrethroid-induced outbreaks of the southern red mite Olygonychus ilicis? Chemosphere 93:1111-1115

Cranham JE, Helle W (1985) Pesticide resistance in Tetranychidae. In: Helle W, Sabelis MW (eds) Spider mites: their biology natural enemies and control. Elservier, Amsterdam, pp 405-422

Croft BA (1990) Arthropod biological control agents and pesticides. Wiley, New York
Cutler GC (2013) Insects, insecticides and hormesis: evidence and considerations for study. Dose-Response 11:154-177

Desneux N, Decourtye A, Delpuech JM (2007) The sublethal effects of pesticides on beneficial arthropods. Annu Rev Entomol 52:81-106

Domingos CA, Melo JWS, Gondim MGC Jr, Moraes GJ, Hanna R, Lawson-balagbo LM, Schausberger P (2010) Diet-dependent life history, feeding preference and thermal requirements of the predatory mite Neoseiulus baraki (Acari: Phytoseiidae). Exp Appl Acarol 50:201-215

Guedes RNC, Cutler GC (2014) Insecticide-induced hormesis and arthropod pest management. Pest Manag Sci 70:690-697

Hamedi N, Fathipour Y, Saber M (2011) Sublethal effects of abamectin on the biological performance of the predatory mite, Phytoseius plumifer (Acari: Phytoseiidae). Exp Appl Acarol 53:29-40

Haq MA, Sumangala K, Ramani N (2002) Coconut mite invasion, injury and distribution. In: Fernando LCP, Moraes GJ, Wickramananda IR (eds) Proceedings of the International Workshop on Coconut Mite (Aceria guerreronis), Coconut Research Institute, Sri Lanka, pp 41-49

Holling CS (1959) Some characteristics of simples types of predation and parasitism. Can Entomol 9:385-396

Holling CS (1961) Principles of insect predation. Ann Rev Entomol 6:163-182

Hua RM, Cao HQ, Xu GW, Tang F, Li XD (2004) The integrative toxicity effects of beta-cypermethrin on Propylea japonica larvae and Aphis gossiypii adults. Acta Phytophysiol Sin $31: 96-100$

Jepson PC (1989) The temporal and spatial dynamics pesticide side effects on non-target invertebrates. In: Jepson PC (ed) Pesticides and non-target invertebrates. Intercept, Wimborne, pp 95-128

Juliano SA (1993) Nonlinear curve fitting: predation and functional response curves. In: Scheiner SM, Gurevitch J (eds) Design and analysis of ecological experiments. Chapman and Hall, New York, pp 159-182

Lawson-Balagbo LM, Gondim MGC Jr, Moraes GJ, Hanna R, Schausberger P (2008) Exploration of the acarine fauna on coconut palm in Brazil with emphasis on Aceria guerreronis (Acari: Eriophyidae) and its natural enemies. Bull Entomol Res 98:83-96

Lima DB, Melo JWS, Gondim MGC Jr, Moraes GJ (2012) Limitations of Neoseiulus baraki and Proctolaelaps bickleyi as control agents of Aceria guerreronis Keifer. Exp Appl Acarol $56: 233-246$

Lima DB, Melo JWS, Guedes RNC, Siqueira HAA, Pallini A, Gondim MGC Jr (2013a) Survival and behavioural response to acaricides of the coconut mite predator Neoseiulus baraki. Exp Appl Acarol 60:381-393

Lima DB, Monteiro VB, Guedes RNC, Siqueira HAA, Pallini A, Gondim MGC Jr (2013b) Acaricide toxicity and synergism of fenpyroximate to the coconut mite predator Neoseiulus baraki. Biocontrol 58:595-605

Lima DB, Melo JWS, Guedes NMP, Gontijo LM, Guedes RNC, Gondim MGC Jr (2015) Bioinsecticide-predator interactions: azadirachtin behavioral and reproductive impairment of the coconut mite predator Neoseiulus baraki. Plosone. doi:10.1371/ journal.pone. 0118343

Melo JWS, Lima DB, Pallini A, Oliveira JEM, Gondim MGC Jr (2011) Olfactory response of predatory mites to vegetative and reproductive parts of coconut palm infested by Aceria guerreronis. Exp Appl Acarol 55:191-202

Melo JWS, Domingos CA, Pallini A, Oliveira JEM, Gondim MGC Jr (2012) Removal of bunches or spikelets is not effective for the control of Aceria guerreronis. HortScience 47:1-5 
Monteiro VB, Lima DB, Gondim MGC Jr, Siqueira HAA (2012) Residual bioassay to assess the toxicity of acaricides against Aceria guerreronis (Acari: Eriophyidae) under laboratory conditions. J Econ Entomol 105:1419-1425

Moore D, Howard FW (1996) Coconuts. In: Lindquist EE, Sabelis MW, Bruin J (eds) Eriophyoid mites: their biology, natural enemies and control. Elsevier, Amsterdam, pp 561-570

Nadimi A, Kamali K, Arabi M, Abdoli F (2009) Selectivity of three miticides to spider mite predator, Phytoseius plumifer (Acari: Phytoseiidae) under laboratory conditions. Agri Sci China 8:326-331

Negloh K, Hanna R, Schausberger P (2011) The coconut mite, Aceria guerreronis, in Benin and Tanzania: occurrence, damage and associated acarine fauna. Exp Appl Acarol 55:361-374

Omoto C, Alves EB, Ribeiro PC (2000) Detecção e monitoramento da resistência de Brevipalpus phoenicis (Geijskes) (Acari: Tenuipalpidae) ao dicofol. An Soc Entomol Bras 29:757-764

Poletti M, Maia AHN, Omoto C (2007) Toxicity of neonicotinoid insecticides to Neoseiulus californicus and Phytoseiulus macropilis (Acari: Phytoseiidae) and their impact on functional response to Tetranychus urticae (Acari: Tetranychidae). Biol Control 40:30-36

Ramaraju K, Natarajan K, Babu PCS, Palnisamy S, Rabindra RJ (2002) Studies on coconut eriophyid mite, Aceria guerreronis Keifer in Tamil Nadu, Índia. In: Fernando LCP, Moraes GJ, Wickramananda IR (eds) Proceedings of the International
Workshop on Coconut Mite (Aceria guerreronis). Coconut Research Institute, Sri Lanka, pp 13-31

Rezác M, Pekár S, Stará J (2010) The negative effect of some selective insecticides on the functional responses of a potential biological control agent, the spider Philodromus cespitum. Biocontrol 55:503-510

SAS Institute (2002) SAS/STAT User's guide, version 8.02, TS level 2 MO. SAS Institute Inc., Cary, North Carolina

Teodoro AV, Fadini MAM, Lemos WP, Guedes RNC (2009) Lethal and sub-lethal selectivity of fenbutatinoxide and sulfur to the predator Iphiseiodes zuluagai (Acari: Phytoseiidae) and its prey, Oligonychus ilicis (Acari: Tetranychidae), in Brazilian coffee plantations. Exp Appl Acarol 36:61-70

Torres JB, Ruberson JR (2004) Toxicity of thiamethoxam and imidacloprid to Podisus nigrispinus (Dallas) (Heteroptera: Pentatomidae) nymphs associated to aphid and whitefly control in cotton. Neotrop Entomol 33:99-106

Van Leeuwen T, Vontas J, Tsagkarakou A, Dermauwa W, Tirry L (2010) Acaricide resistance mechanisms in the two spotted spider mite Tetranychus urticae and other important Acari: a review. Insect Biochem Mol Biol 40:563-572

Wang XY, Shen ZR (2002) Effects of sublethal doses of insecticides on predation of multicolored asian ladybird Harmonia axyridis (Pallas) (Coleoptera: Coccinelliodae). Acta Ecol Sin 22: 2278-2284 